\title{
Evaluation of the impact of adjusting the angle of the axis of a wind turbine rotor relative to the flow of air stream on operating parameters of a wind turbine model
}

\author{
Stanisław Gumuła ${ }^{1 *}$, Małgorzata Piaskowska - Silarska ${ }^{2}$, Krzysztof Pytel $^{2}$, Henryk Noga $^{2}$, \\ Wojciech Kulinowski ${ }^{2}$ \\ ${ }^{1}$ AGH University of Science and Technology, al. Mickiewicza 30, 30-059 Kraków, Poland \\ ${ }^{2}$ PU of Cracow, ul. Podchorążych 2, 30-084 Kraków, Poland
}

\begin{abstract}
The aim of this study was to determine the effect of regulation of an axis of a wind turbine rotor to the direction of wind on the volume of energy produced by wind turbines. A role of an optimal setting of the blades of the wind turbine rotor was specified, as well. According to the measurements, changes in the tilt angle of the axis of the wind turbine rotor in relation to the air stream flow direction cause changes in the use of wind energy. The publication explores the effects of the operating conditions of wind turbines on the possibility of using wind energy. A range of factors affect the operation of the wind turbine, and thus the volume of energy produced by the plant. The impact of design parameters of wind power plant, climatic factors or associated with the location seismic challenges can be shown from among them. One of the parameters has proved to be change settings of the rotor axis in relation to direction of flow of the air stream. Studies have shown that the accurate determination of the optimum angle of the axis of the rotor with respect to flow of air stream strongly influences the characteristics of the wind turbine.
\end{abstract}

\section{Introduction}

All over the world there are areas where wind energy can be used to produce energy in a commercially reasonable manner. Therefore, the power of newly built wind power plants is constantly increasing, there are more of them and they are bigger. Grouping of the plants in ecologically justified locations of wind farms results in the need to reduce the distance between objects. [1]. Power plants that are located too close to one another may disturb the direction of the wind flow and the changing wind direction can affect the amount of energy obtained by the wind power plant. [2]. Essential elements of the wind power plant are the tower, nacelle and rotor. The tower holds the weight of the rotor and nacelle while being resistant to vibrations and the effects of fatigue resulting from wind pressure and cyclic rotation of the rotor blades. Nacelle includes gears, generator and control systems managing

\footnotetext{
* Corresponding author: stangum@gmail.com
} 
the work and setting of the rotor of power plant. At the rotor wheel there is the conversion of wind energy into mechanical energy. Moving away the rotor axis of wind turbine from the main wind direction causes change in the effective area of the rotor work and consequently the differences in the amount of obtained energy. Positioning mechanism for the optimum direction enabling maximum use of wind energy plays a role in the efficient use of wind energy. A mechanism tracking the wind direction and the position of a nacelle, managed by an electronic system, turns the nacelle slightly during the changes in wind direction. Right positioning of the rotor of wind power plant is an extremely important element of the aero energy system. [3].

Wind energy is a rapidly growing global economic sector. [4]. In comparison with the solar energy, it is characterized by lower costs per $1 \mathrm{kWh}$ and comparing it with geothermal energy less technical obstacles will be encountered. Use of wind energy is convenient as the wind blows in virtually every place on the globe, near the land, the ocean or high above the surface of our planet.

The efficiency of energy production from wind varies. This is related to constantly changing climatic conditions and different regions of the world. A good complement to energy production is usually between wind and solar energy, which are the two most suited renewable sources of energy. A good solution is the creation and operation of hybrid wind and solar energy systems, optimally matching energy installations for the effective and economical use of energy resources. In order to optimize the operation of such plants, it is important to determine the operating parameters of both systems, i.e. solar and wind power installations [5-10].

The aim of this study was to determine the effect of regulation of an axis of a wind turbine rotor to the direction of wind on the volume of energy produced by wind turbines.

\section{Power coefficient and tip speed ratio}

Wind turbine may be designed as a device with a horizontal or vertical axis of rotation of rotor. Horizontal axis wind turbines have a rotor mounted to a nacelle. The rotors have not the same amount of blades, but often there are three blades in rotor. Rotor blades are crucial elements of wind turbine because of their ability to capture wind energy. Design and dimensions of the rotor blades have a substantial influence on an energy output. Rotor blades drive a generator, that produce planned amount of energy. A produced energy can be shown as a power output in Watts and in non-dimensional form as a power coefficient $\mathrm{C}_{\mathrm{p}}$ [Fig. 1].

where:

$$
C_{p}=2 \frac{P}{\rho V_{0}^{3} A}
$$

$\mathrm{C}_{\mathrm{p}}$ - power coefficient;

$\mathrm{P}$-power, $\mathrm{W}$;

$\rho-$ density of air, $\mathrm{kg} / \mathrm{m}^{3}$;

$\mathrm{V}_{0}$ - wind speed, $\mathrm{m} / \mathrm{s}$;

$\mathrm{A}$ - area of a rotor, $\mathrm{m}^{2}$, given by: $\mathrm{A}=\pi \mathrm{R}^{2}$.

A maximum value of a theoretical $C_{p}$ stand for $C_{P \max }=16 / 27=0.593$ and is defined as the so-called Betz limit. Contemporary wind turbines work with $C_{p}$ up to about 0.5 . Figure 1 shows that presented wind turbine has a maximum efficiency of approximately $\mathrm{C}_{\mathrm{p}}=0.3$ for a wind speed between 6 and $8[\mathrm{~m} / \mathrm{s}]$.

Tip speed ratio refers to the wind speed and the speed of the tips of the blades of wind turbine. It is calculated as: 


$$
\lambda=\omega R / V_{0}
$$

where:

$\lambda$ - tip speed ratio;

$\omega$ - rotational speed, rpm;

$\mathrm{R}$ - radius of the rotor, $\mathrm{m}$;

$\mathrm{V}_{0}-$ wind speed, $\mathrm{m} / \mathrm{s}$.

Power coefficient can be presented as a function of the tip speed ratio $\lambda$ (TSR). [Fig. 2]. TSR vary with rotational and wind speed. Generally, the greater number of blades, the lower is the tip speed ratio. [11-13].
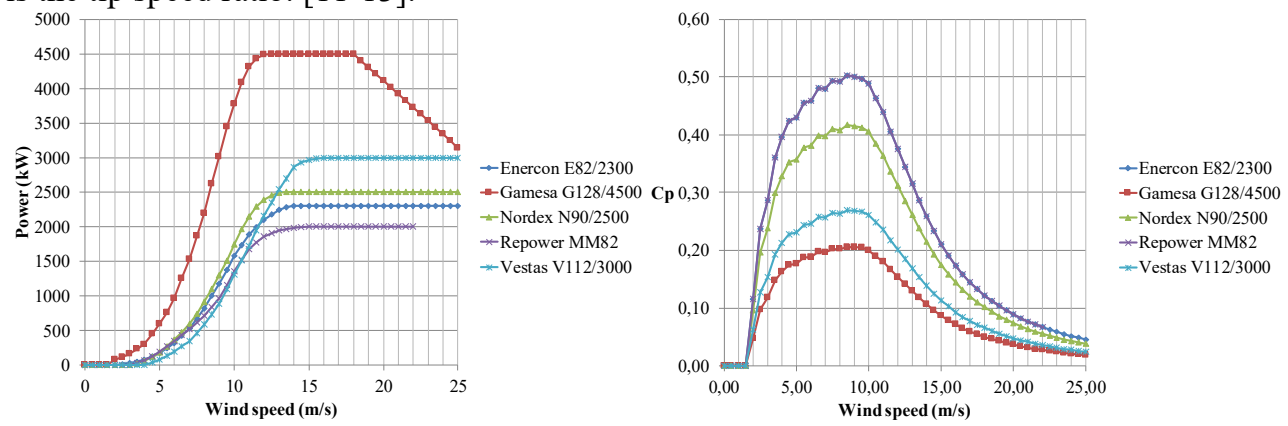

Fig. 1. Comparison between sample power curve (left) and power coefficient (right) as a function of the wind speed, [14].

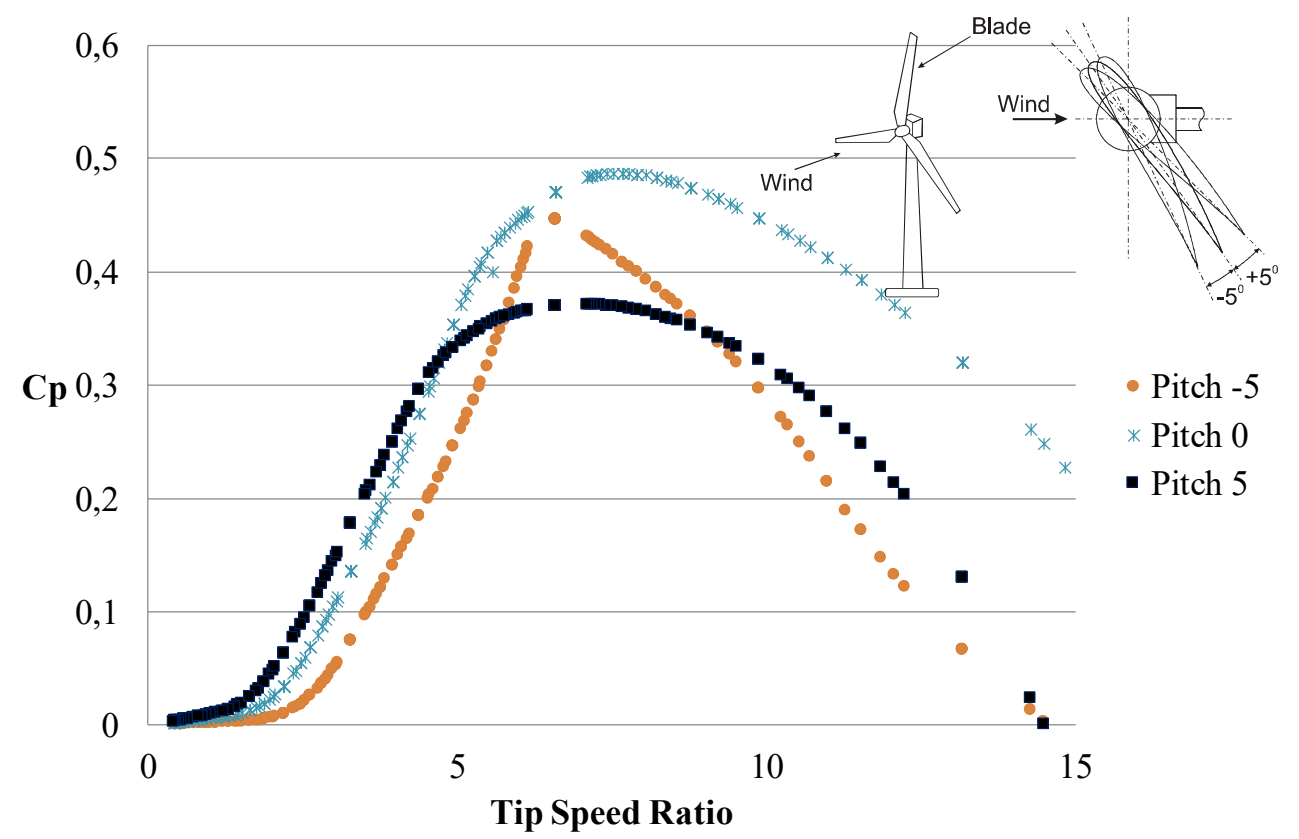

Fig. 2. Comparison between sample $C_{p}$ curve and TSR for pitch values: $-5,0$ and 5 . Insert shows a coordinate system applied in research.

The angle of the axis of the rotor in relation to the direction of flow of the air stream is one of the factors that make the system work efficiently. 


\section{Experimental procedure}

The aim of the research is to determine the impact of the setting of the rotor axis of the power plant towards the wind direction on the amount of energy produced by the wind power plant. Moreover, the role of optimal setting of the blades of the power plant in the rotor towards the wind direction was specified.

The measurements were carried out on the test position, which allows research on models of wind power plants working in conditions close to real. The drive system of the tunnel is composed of sixteen axial fans with capacity of $3,800 \mathrm{~m}^{3} / \mathrm{h}$ at a rotational speed of $2300 \mathrm{rpm}$. controlled independently by inverter. Before entering the measurement space the air stream passes through the system consisting of the diffuser and bundle-pipe straightener. In order to increase the speed of the air flow and align its velocity profile, the tunnel was tightly connected with Witoszyński type shape nozzle.

In the test space the model of wind power plant with a rotor of $0.5 \mathrm{~m}$ was placed. The power plant was connected with the control and register unit, which measured the torque and rotational speed of the rotor and therefore the power on the power plant shaft. The recording system performs acquisition of torque and rotational speed. The AT2016 used for measurements is a multifunction analog and digital I/O card that features the measurement and control functions for PC/AT systems: D/A and A/D conversion, digital input/output and vounter/timer. It has 16 analogue and 8 digital channels, the sampling rate from $0.002[\mathrm{~Hz}]$ to $200[\mathrm{kHz}]$, the input signal is $\pm 5[\mathrm{~V}]$. The maximum measuring error does not exceed $\pm 0.07 \%$. A measuring computer was equipped with an electronic signal acquisition module E.S.A.M. that recorded more than 20,000 samples of each measured values during the tests. The measuring system in a power plant was composed of two sets. The first one measured the speed of the fan using the optical method. Torque measurement was made using a strain gauge torquemeter mounted in such a configuration to change a torque into a beam bending [Fig. 3].

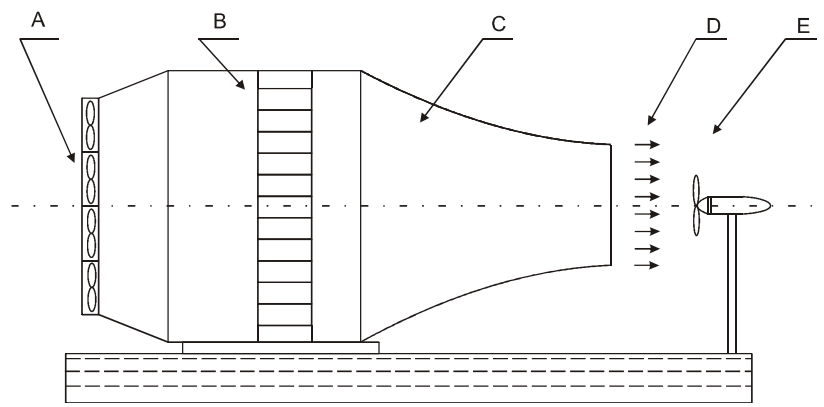

Fig. 3. Test position: A - system of fans forcing the air flow, B - the pipe straightening the air flow, $\mathrm{C}$ - the Witoszyński nozzle, $\mathrm{D}$ - the air stream of given parameters, $\mathrm{E}$ - the model wind power plant.

\section{Results and discussion}

Analyses of the impact of specific working conditions on the produced energy have been conducted for the model wind power plant. Measurements of the impact of changes in the direction of the rotor axis towards the flow direction of the air stream on the operating of a model wind power plant was carried out for the power plant with the three-bladed rotor with profiled blades. The measurements were carried out for five air stream velocities $4.3 \mathrm{~m} / \mathrm{s}$, $5.3 \mathrm{~m} / \mathrm{s}, 7.1 \mathrm{~m} / \mathrm{s}, 7.9 \mathrm{~m} / \mathrm{s}$ and $11.5 \mathrm{~m} / \mathrm{s}$. The angle of deviation of the rotor axis from the direction of the air stream was $0^{\circ}, 10^{\circ}, 20^{\circ}, 30^{\circ}$ and $45^{\circ}$. Results of chosen measurements are presented in the charts showing the changes of power coefficient $\left(C_{p}\right)$, depending on the tip speed ratio $(\lambda)$ for selected values of the angle between the direction of flow of the air stream 
and the direction of the setting of the rotor axis and the selected flow rate of the air stream $\left(\mathrm{V}_{0}\right)$.

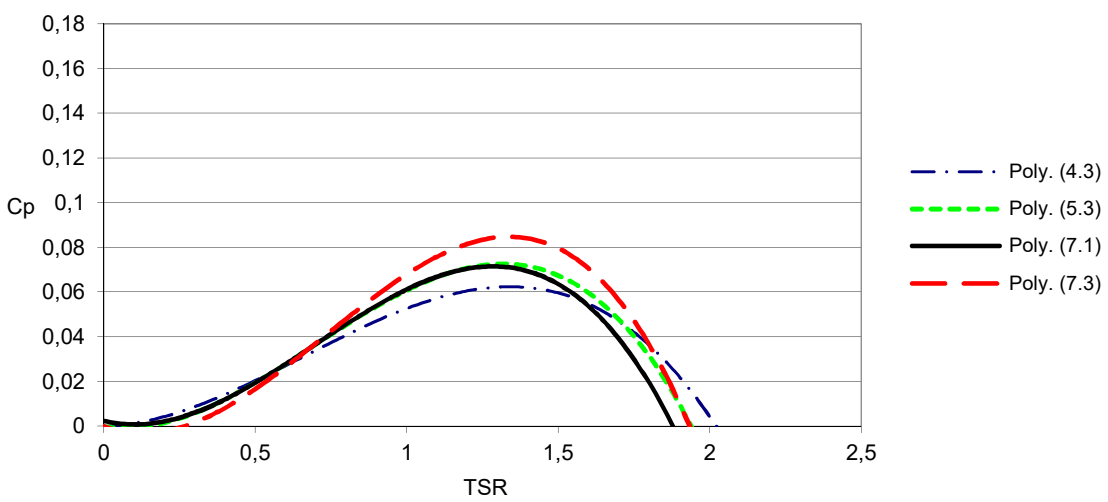

Fig. 4. Changes in $\mathrm{Cp}=\mathrm{f}(\lambda)$ for the angle of $0^{\circ}$ between the direction of flow of the air stream and the direction of the rotor axis for the selected wind speed values $4.3-7.3 \mathrm{~m} / \mathrm{s}$.

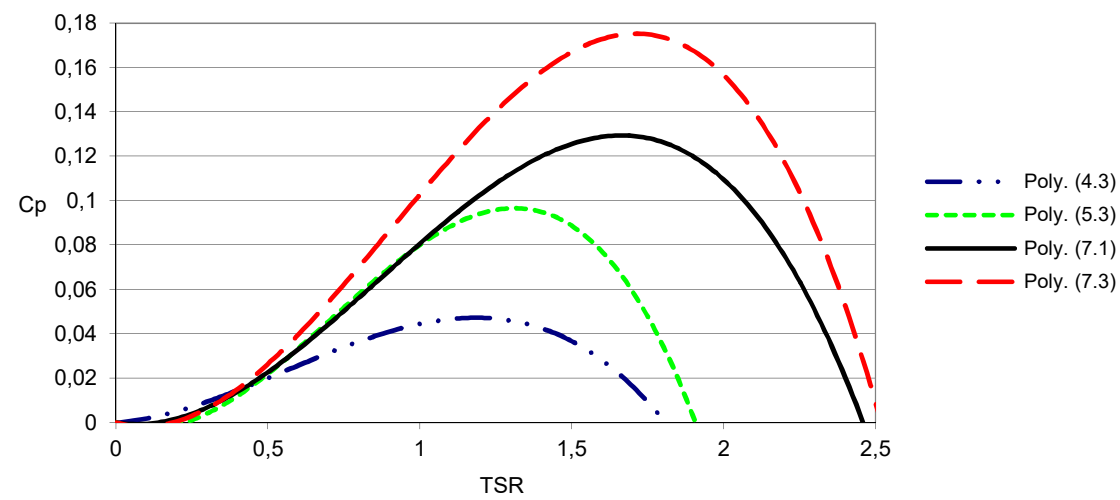

Fig. 5. Changes in $\mathrm{Cp}=\mathrm{f}(\lambda)$ for the angle of $10^{\circ}$ between the direction of flow of the air stream and the direction of the rotor axis for the selected wind speed values $4.3-7.3 \mathrm{~m} / \mathrm{s}$.

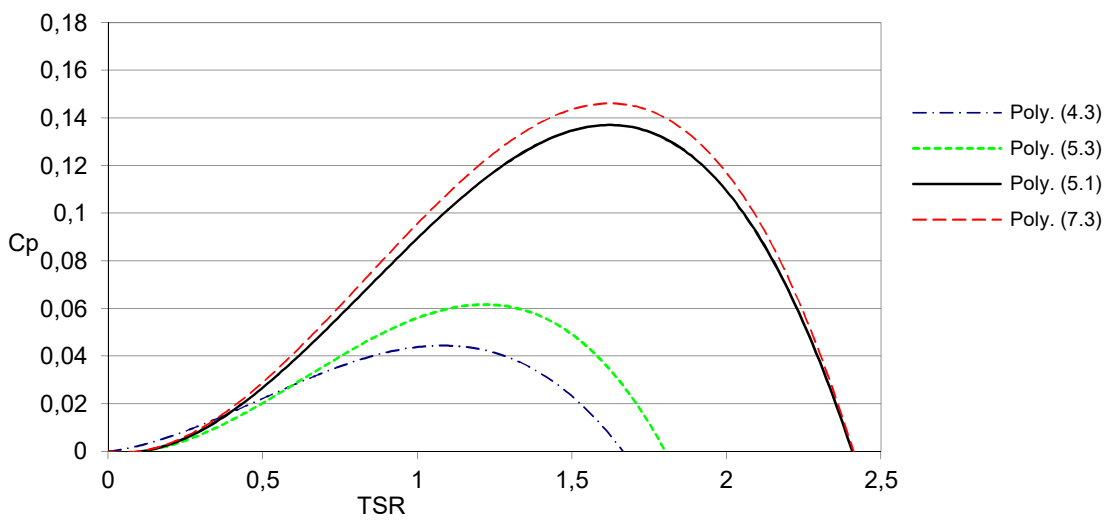

Fig. 6. Changes in $\mathrm{Cp}=\mathrm{f}(\lambda)$ for the angle of $20^{\circ}$ between the direction of flow of the air stream and the direction of the rotor axis for the selected wind speed values $4.3-7.3 \mathrm{~m} / \mathrm{s}$. 


\section{Energy and Fuels 2016}

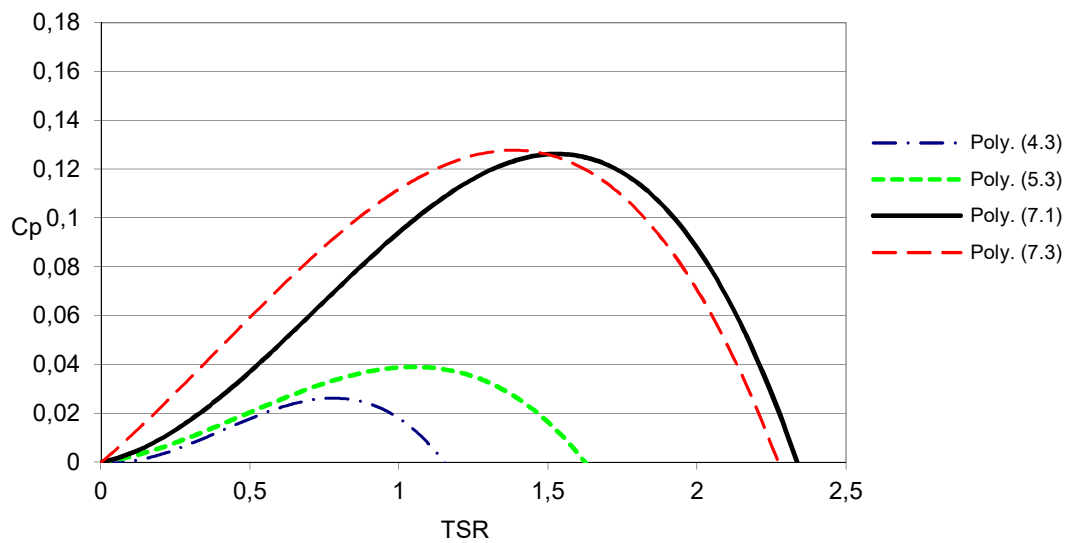

Fig. 7. Changes in $\mathrm{Cp}=\mathrm{f}(\lambda)$ for the angle of $30^{\circ}$ between the direction of flow of the air stream and the direction of the rotor axis for the selected wind speed values $4.3-7.3 \mathrm{~m} / \mathrm{s}$.

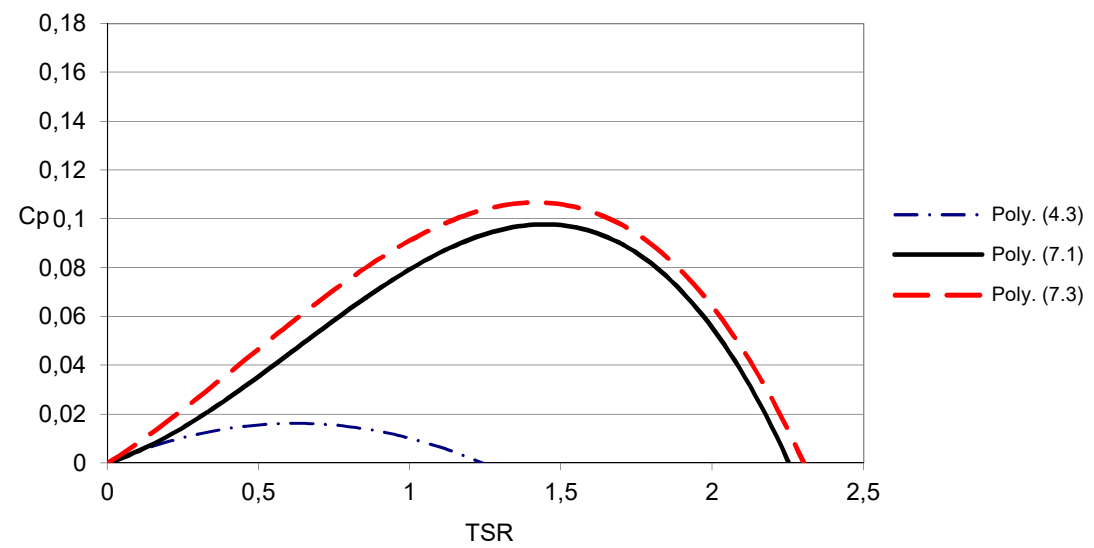

Fig. 8. Changes in $\mathrm{Cp}=\mathrm{f}(\lambda)$ for the angle of $45^{\circ}$ between the direction of flow of the air stream and the direction of the rotor axis for the selected wind speed values $4.3-7.3 \mathrm{~m} / \mathrm{s}$.

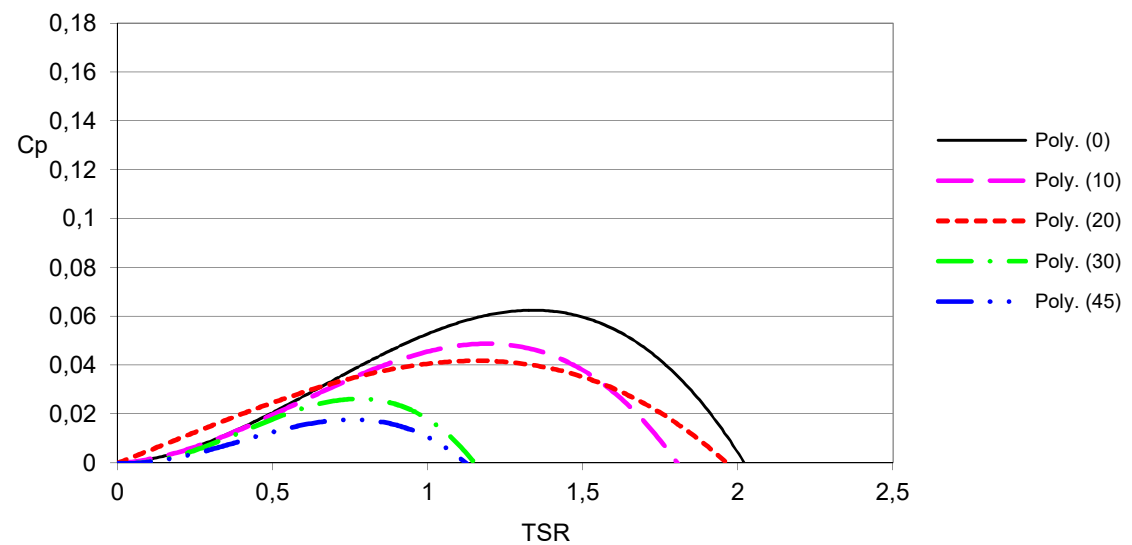

Fig. 9. Changes in $C p=f(\lambda)$ for the speed of air stream flow $v=4.3 \mathrm{~m} / \mathrm{s}$ for the selected angles between the direction of flow of the air stream and the direction of the rotor axis $\left(0\right.$ to $\left.45^{\circ}\right)$. 
Figures from 4 to 8 describe the changes in $C_{p}=f(\lambda)$. The results were approximated with polynomial of degree 3 . It has been observed that for the angle of $0^{\circ}$ the $C_{p}$ maximum values for the test model wind power plant, regardless of the set speeds, are similar and in the range of 0,06-0,085. The maximum $\lambda$ value is also comparable for the $\mathrm{C}_{\mathrm{pmax}}$. At the same time it was observed that for an angle of $10^{\circ}$ the $C_{p}$ values are the maximum out of the analysed variants, hence the conclusion is that the amount of energy from the wind is the greatest. It was observed that with increasing the speed of moving air mass the value of $\mathrm{C}_{\mathrm{p}}$ raises as well. Simultaneously, change in the value of angle between the direction of flow of the air stream and the direction of setting of the rotor axis affects the change in value of tip speed ratio. Increase in speed means raise of the maximum value of tip speed ratio.

Figures from 9 to 12 describe the changes in $C_{p}=f(\lambda)$ for permanent values of flow velocity of the air stream for a variable angle between the direction of flow of the air stream and the direction of the axis of the rotor.

Increasing the value of the angle of deviation of the axis of a power plant from the flow direction of the air stream reduces the use of wind energy. For the tested speeds of 4.3 and $5.3 \mathrm{~m} / \mathrm{s}$ the use of wind energy decreases along with increase in the angle of deviation of the axis of power plant from the direction of the air inflow. For the air stream speed of 7.1 and $7.3 \mathrm{~m} / \mathrm{s}$, the use of wind energy increases at the beginning and then decreases along with increasing the yaw angle of the axis of power plant. The greatest use is for the angle of $10^{\circ}$, the smallest for the angle of $0^{\circ}$. Power plant at an angle of $10^{\circ}$ uses pressure of wind stream on the blades of power plant. The increase in speed means that for the angle of $0^{\circ}$ the $C_{p}$ value increases slightly, whereas for $10^{\circ}$ it grows rapidly. The power plant uses the power of pressure of the air stream.

The analysed wind power plant model is characterized by low efficiency. A diameter of a measurement space is 1.4 [m]. A model wind turbine with a rotor diameter no more than half of the test section was placed in the measurement space. For small wind turbines like the wind tunnel model, the Low-Reynolds-Number effects will diminish the performance significantly. The real wind power plants reach $\mathrm{Cp}$ up to about $50 \%$. However, the actual relationship between the deviations of the rotor axis towards the free airflow can be estimated.

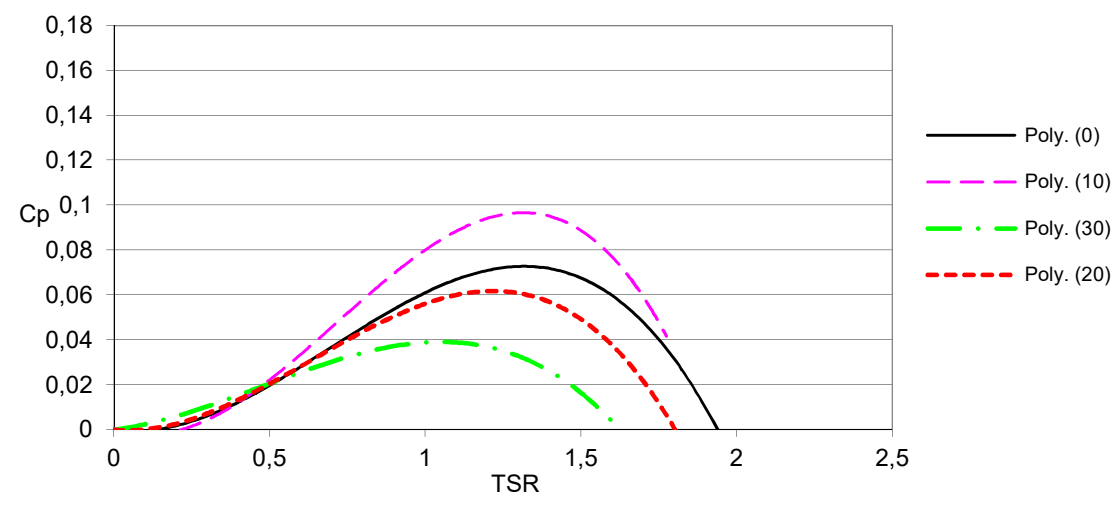

Fig. 10. Changes in $C p=f(\lambda)$ for the speed of air stream flow $v=5.3 \mathrm{~m} / \mathrm{s}$ for the selected angles between the direction of flow of the air stream and the direction of the rotor axis $\left(0\right.$ to $\left.45^{\circ}\right)$. 


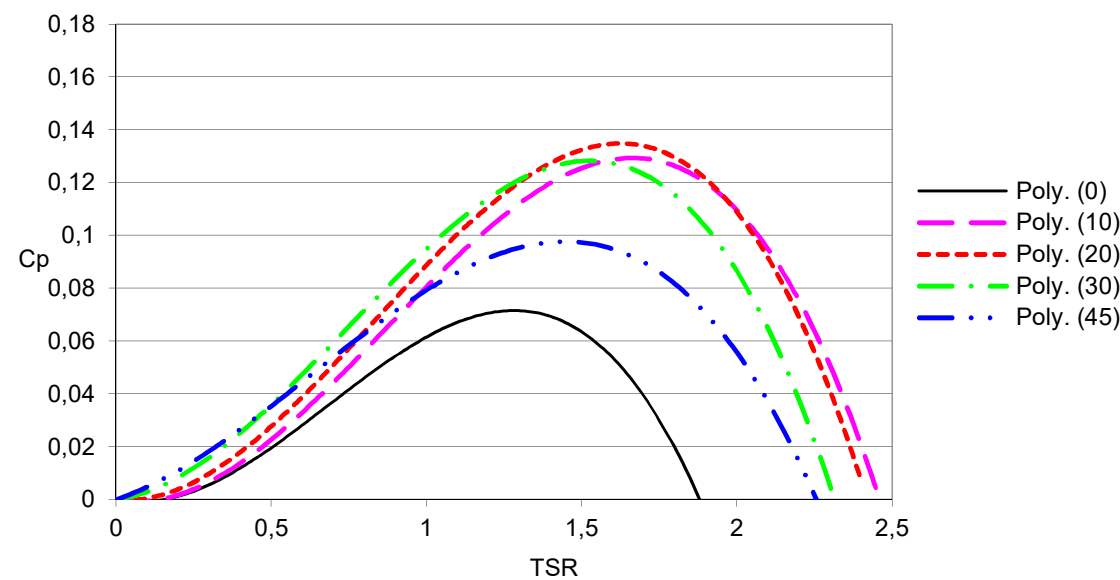

Fig. 11. Changes in $C p=f(\lambda)$ for the speed of air stream flow $v=7.1 \mathrm{~m} / \mathrm{s}$ for the selected angles between the direction of flow of the air stream and the direction of the rotor axis $\left(0\right.$ to $\left.45^{\circ}\right)$.

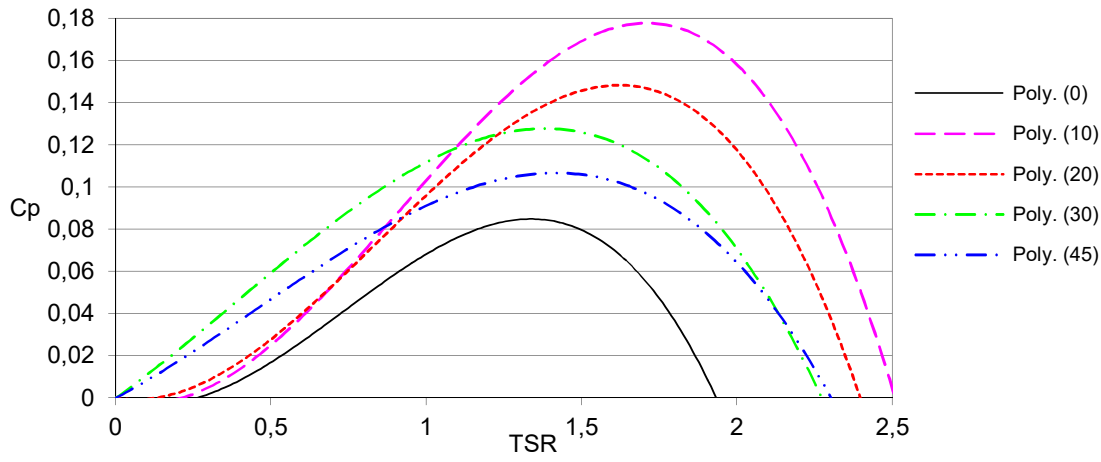

Fig. 12. Changes in $C p=f(\lambda)$ for the speed of air stream flow $v=7.3 \mathrm{~m} / \mathrm{s}$ for the selected angles between the direction of flow of the air stream and the direction of the rotor axis $\left(0\right.$ to $\left.45^{\circ}\right)$.

\section{Summary}

The performances of chosen wind turbines have been analysed. The publication explores the issues of the operating conditions of wind turbines on the possibility of using wind energy. A number of factors affect the operation of the wind power plant, and thus the amount of the energy produced by the plant [13-15]. Among them, we can isolate the impact of the structural parameters of the wind power plant [16-20]. wind turbine drive and control systems [21-26], materials of components of the wind turbines [27-35], climatic factors or seismic events associated with the location [36-39].

Wind is considered as relatively well-known carrier of a low carbon source of energy. Throughout the world, there are areas where wind energy can be used in power plants in a commercially reasonable manner. Therefore, power of constructed wind power plants steadily increases. Number of them is increasing and they are getting larger, as well. Grouping of wind turbines in ecologically justified wind farms results in a need to reduce a distance between individual objects. Wind turbines located too close to each other can interfere with the flow direction of wind and wind direction changes can affect the amount of energy generated by wind turbine. 
One of the parameters proved to be the change of setting or the rotor axis towards the direction of the air stream flow. [40-45]. Studies showed that accurate determination of the optimum angle of the axis of the rotor towards the flow of the air stream very strongly influences the characteristics of the wind power plant.

\section{References}

1. S. Gumula, K. Pytel, M. Piaskowska-Silarska, Polish Journal of Environmental Studies, 23 (2014) 2315-2320.

2. W. Hudy, K. Jaracz. K. Pytel, International Carpathian Control Conference 16 (2015) $81-185$.

3. S. Gumuła, T. Knap, Determination of the optimal geometry and movement parameters of the wind power plants depending on the average annual wind speed. National Forum "Small Energy - '97." Zakopane 1997.

4. S. Gumula, W. Hudy, M. Piaskowska-Silarska, K. Pytel, Chemical Industry, 94 (2015) $1000-1003$.

5. S. Gumula, K. Pytel, M. Piaskowska-Silarska, Polish Journal of Environmental Studies, 23 (2014) 2321-2325.

6. H. Noga, Information technologies and technical education 1 (2009) 165-169.

7. I. Turekova, J. Depesova, A. Haskova, T. Bagalova, EDULEARN 15 (2015) 1913-1921.

8. K. Pytel, W. Hudy, H. Noga, W. Kulinowski, International Carpathian Control Conference 17 (2016) 401-406.

9. K. Pytel, W. Hudy, H. Noga, W. Kulinowski, International Carpathian Control Conference 17 (2016) 407-412.

10. K. Pytel, K. Jaracz, S. Gumula, International Carpathian Control Conference 13 (2012) 592-595.

11. T. Chmielniak, Basic theory of profiles and palisades vane. Warsaw PAN 1989.

12. J. Elsner: Aerodynamics of the palisades vane. Warsaw PAN 1989.

13. J. Madejski: The treaty of propellers. Wroclaw Ossolineum 1991.

14. http://www.thewindpower.net, access Jan $1^{\text {st }}, 2017$

15. R. Carriveau, Fundamental and Advanced Topics in Wind Power, InTech, 2011.

16. G. Ronsten, Journal of Wind Engineering and Industrial Aerodynamics 39.1 (1992) 105118.

17. Chen, Jin, et al. Applied Mathematical Modelling 40.3 (2016): 2002-2014.

18. P. Krajewski, Ł. Flaga, A. Flaga, Technical Transactions Civil Engineering (2016) 8191.

19. Fischer, Gunter Reinald, Timoleon Kipouros, and Anthony Mark Savill, Renewable Energy 62 (2014) 506--515.

20. Spinato, F., et al. "Reliability of wind turbine subassemblies." IET Renewable Power Generation 3.4 (2009) 387-401.

21. R. Jablonski, M. Turkowski, R. Szewczykn (Eds.). Recent Advances in Mechatronics. Proceedings of 7th International Symposium Mechatronics held Sept. 19-21 in Warsaw, Poland. 2007.

22. F.D. Bianchi, H. de Battista, R.J. Hernán, Wind Turbine Control Systems. Principles, Modelling and Gain Scheduling Design, Springer, 2007.

23. L. Borowik, P. Ptak, Przeglad Elektrotechniczny 88 (2012) 142-145.

24. T. Prauzner, Electrotechnical overview 88 (2012) 205-208.

25. Keung, Ping-Kwan, et al. IEEE Transactions on Power Systems 24 (2009) 279-287.

26. A. Björn, J. Birk. A high power density converter system for the Gamesa G10x 4, $5 \mathrm{MW}$ wind turbine. European Conference on Power Electronics and Applications (2007) 1-8. 
27. K. Pytel, J. Suchanicz. M. Livinsh, A. Sternberg, Phase Transitions. 87 (2014) 11811190.

28. J. Suchanicz, B. Garbarz-Glos, G. Stopa, T. Kruzina, J. Kusz, M. Zubko, W. Hofmeister, I. Jankowska-Sumara, D. Wcisło, K. Konieczny, R. Rosiek, A. Finder, K. Pytel, M. Dambekalne, A. Sternberg, Integrated Ferroelectrics 108 (2009) 98-105.

29. K. Pytel, J. Suchanicz, M. Livinsh, A. Sternberg, Condens. Matter Phys., 16 (2013) 31706.

30. Lavassas, I., et al. Engineering structures 25.8 (2003) 1097-1106.

31. J. Suchanicz, A. Finder, I. Smeltere, K. Konieczny, I. Jankowska-Sumara, B. GarbarzGlos, M. Sokolowski, R. Bujakiewicz-Korońska, K. Pytel, M. Antonova, A. Sternberg, Integrated Ferroelectrics, 123 (2011) 102-107.

32. J. Suchanicz, G. Stopa, J. Kusz, M. Zubko, W. Hofmeister, M. Antonova, A. Kalvane, M. Dambekalne, A. Sternberg, I. Jankowska-Sumara, B. Garbarz-Glos, D Wcisło, K. Konieczny, K. Pytel, A. Finder, Journal of Materials Science 45 (2010) 1453-1458.

33. P. Dulian, B. Garbarz-Glos, W. Bąk, M. Antonova, C. Kajtoch, K. Wieczorek-Ciurowa, H. Noga, Ferroelectrics 497 (2016) 62-68.

34. B. Garbarz-Glos, W. Bąk, H. Noga, M. Antonova, A. Kalvane, W. Śmiga, Integrated Ferroelectrics 173 (2016) 12-18.

35. W. Śmiga, B. Garbarz-Glos, W. Piekarczyk, H. Noga, D. Sitko, M. Karpierz, M. Livinsh, Integrated Ferroelectrics 173 (2016) 46-52.

36. W. Sobczyk, K. Sternik, E.J. Sobczyk, H. Noga, Envoronmental protection. 17 (2015) 1113-1124.

37. Jonkman, Jason Mark. Dynamics modeling and loads analysis of an offshore floating wind turbine. ProQuest, 2007.

38. A. Bergek, S. Jacobsson. The emergence of a growth industry: a comparative analysis of the German, Dutch and Swedish wind turbine industries. Change, transformation and development. Physica-Verlag HD (2003) 197-227.

39. M. Wolsink, Renewable and sustainable energy reviews 11.6 (2007) 1188-1207.

40. G. Bir, Multiblade coordinate transformation and its application to wind turbine analysis. ASME Wind Energy Symposium (2008) 1-17.

41. M. Korczyński, R. Głowski, S. Opaliński, S. Czaban, The utilization of wind-tunnel to estimate the dust content of chosen bedding materials. ISAH-2007 Tartu, Estonia. 2007.

42. Howell, Robert, et al. Renewable energy 35.2 (2010) 412-422.

43. G. Ahmad, Ghulam, anA. Uzma. Renewable Energy 101 (2017) 286-292.

44. W. Yang, et al. Wind Energy 17.5 (2014) 673-693.

45. C. Kaidis, U. Bahri F. Amoiralis. IET Renewable Power Generation 9.8 (2015) 892 899. 